\title{
Investigations for obtaining desired strength of Nylon6 and Fe powder-based composite wire for FDM feedstock filament
}

\author{
Harish K. Garg ${ }^{1} \cdot$ Rupinder Singh ${ }^{2}$
}

Received: 1 June 2016/Accepted: 20 April 2017/Published online: 26 April 2017

(C) Springer International Publishing Switzerland 2017

\begin{abstract}
In the present work, an effort has been made for modelling the peak strength of Nylon6-Fe powder composite-based feedstock filament (wire) for fused deposition modelling (FDM) process. The developed filament has been used to prepare functional prototypes with ferromagnetic characteristics. The methodology involves the use of historical data approach of response surface methodology (RSM) to study the effect of input process parameters (namely: barrel temperature, die temperature, screw speed, speed of the winding machine of single screw extruder and melt flow index of composite material as rheological property) on peak strength of the filament developed. The model for prediction of peak strength of Nylon6-Fe powder composite filament has been counter verified by actual experimentation. Further, the results of the study also highlights that Nylon6-Fe composite-based FDM filament enabled successful run of this material without any change in hardware/software of the commercial FDM setup.
\end{abstract}

Keywords Fused deposition modelling - Wire strength . Acrylonitrile butadiene styrene $\cdot$ Screw extruder . Composite wire

Rupinder Singh

rupindersingh78@yahoo.com

1 Department of Mechanical Engineering, MRSPTU Bathinda, Bathinda, India

2 Department of Production Engineering, GNDEC Ludhiana, Ludhiana, India

\section{Introduction}

Rapid manufacturing (RM) is considered as one of the revolution of 21 st century and its opportunities and advantages are extensive [1]. RM parts are made by using additive manufacturing (AM) technologies and practically no waste material is generated [2]. Moreover, RM can be used in the case of even complex geometries and has given freedom for new designs [3]. However, the tooling that is required for manufacturing demands a sizeable investment and a significant time is spent on the design of the product [4]. RM is an enabling technology since it eliminates the upfront expense and expedites manufacturing [5]. Reduction of product development cycle time is a major concern in industries to remain competitive in the market place. Hence, focus has shifted from traditional product development methodology to rapid fabrication techniques [6]. With the idea of improvement of accuracy and materials is considered, it can be envisioned to upgrade the conventional techniques to so-called RM techniques in which the single parts are made which will be the end product rather than being a prototype [7].

Commercially, FDM (which is one of the cost effective AM technology) uses ABS wire for production of RP models. Some reported studies highlight that as a substitute, metal polymer feed stock is prepared by mixing the proportions of metals and polymers in powder form. With this, the high-performance thermoplastic composite for FDM process has been developed [8]. Further surfactants and plasticizers are added to improve the flow, stiffness and viscosity of the feed stock filament [9]. This composite have thermo-tropic liquid crystal fibres, post processed by dual extrusion process. The parts obtained by FDM using this composite material have tensile modulus and strength four times than acrylonitrile butadiene styrene (ABS). 
Product features, quality, cost, and time to market are the important factors for a manufacturer to remain competitive and for this AM offers an opportunity to make products faster and usually at a lower price than the conventional methods [10-12]. FDM is second most widely used AM technology, after Stereo-lithography, in which a filament of acrylonitrile-butadiene-styrene (ABS) material is used [13]. ABS has good mechanical properties and recently polycarbonate and polysulfonic materials have been introduced with greater strength and temperature range [14]. FDM is cheaper than other AM machines with low maintenance and is extensively used for commercial applications [13]. After the research of 20 years, the AM continues to grow with the addition of new technologies, methods and applications [15]. For fabricating functional components by FDM, some researchers have developed new metallic and ceramic materials of high mechanical and thermal properties to fulfil the requirements of application.

Rutgers University in the USA have developed fused deposition ceramics (FDC) and metals for industrial applications. A variety of ceramic and metallic materials such as silicon nitrate, aluminium oxide, hydroxypatite and stainless steel are selected for a variety of structural, electroceramic and bioceramics applications [8]. Modern RM processes uses computer-aided design-based automated, AM techniques to construct parts that are used directly as finished products or components. Although current RM systems are being successfully used in specialist applications for the production of end-user parts, however, many problems are still unsolved [16].

\section{Fused deposition modelling}

FDM machine dispenses two materials from which one material is used to build the part, while the other is used for the support structures. The material in the form of wire is supplied to the head of the machine from a spool. The filament is fed into a temperature-controlled head and heated to a semi-liquid state to produce the part. The head extrudes and deposits the material in thin layers onto a fixtureless base $[17,18]$. The head directs the material into place with precision, as each layer is extruded; it bonds to the previous layer and solidifies. The designed object emerges as a solid three-dimensional part without the need for tooling. The FDM machine operates in $X-, Y$ - and $Z$ axes, drawing the model one layer at a time. The .STL file of a model is imported into pre-processing software of the FDM machine and after reviewing the path data and generating the tool paths; the data is transferred into the FDM machine. The best orientation is chosen and the part is sliced into horizontal layers varying from \pm 0.127 to

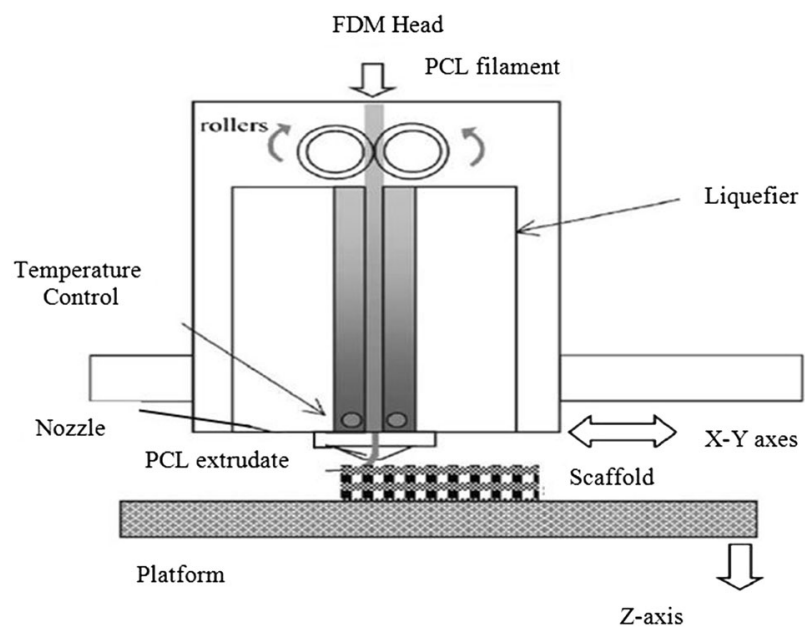

Fig. 1 Schematic of FDM [20]

$0.254 \mathrm{~mm}$ thickness. A support structure is created where needed which is based on the position and geometry of the part. Once the part is completed the support structures are removed and the surface is finished [10]. A key requirement for any material to be used in FDM is compatibility of material with existing FDM setup without changing functional hardware/software of machine. Apart from compatibility, mechanical properties of material arealso important to explore its industrial applications [19]. The FDM process has been shown in Fig. 1.

\section{Screw extruder}

The single screw extruder has been used to prepare the composite wire to be finally used on the FDM setup. The schematic of the screw extruder is shown in Fig. 2.

The variable parameters of extrusion process are: barrel temperature, screw speed, die temperature, take up unit speed, water tank temperature and die nozzle diameter. The various specifications of single screw extruder for the fabrication of filament are shown in Table 1 . The die nozzle diameter is $4 \mathrm{~mm}$, and the diameter of extruded filament was controlled by adjusting take up unit speed and water tank temperature.

The barrel was hard tempered in order to reduce the friction and wear during the processing of composite materials. The screw and die nozzle was chrome plated so that material flows continuously without sticking with screw and nozzle surface. Four parameters such as material composition, barrel temperature, die temperature and screw speed were selected. The single screw extruder barrel consist of three heaters (Heater 1, Heater 2 and Heater 3) each having a capacity of $1 \mathrm{KW}$ and equipped with zone temperature control (see Fig. 3). 
Fig. 2 Schematic of screw extruder [21]

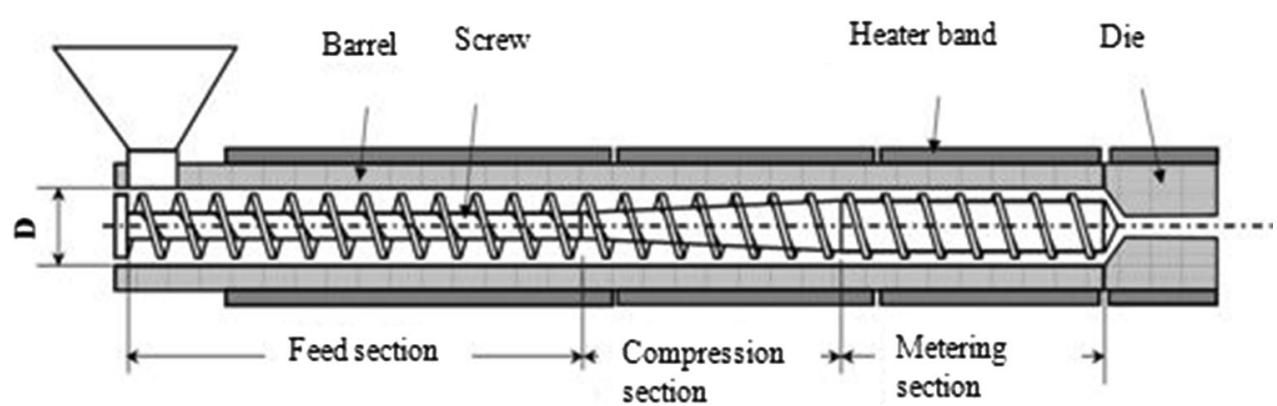

Table 1 Specifications of single screw extruder

\begin{tabular}{|c|c|c|c|c|c|}
\hline \multirow[t]{2}{*}{ Screw diameter $(\mathrm{mm})$} & \multirow[t]{2}{*}{$L / D$ ratio } & \multicolumn{2}{|c|}{ Number of heaters installed } & \multirow[t]{2}{*}{ Screw speed (rpm) } & \multirow[t]{2}{*}{ Take up unit speed (rpm) } \\
\hline & & Barrel & Die & & \\
\hline 25.0 (metric) & $26: 1$ & 3 & 1 & $0-40$ & $0-40$ \\
\hline
\end{tabular}

Additionally, water cooling temperature control system is also available. The barrel length is $750 \mathrm{~mm}$, and each heater is placed with a gap of $80 \mathrm{~mm}$. The 'heater 1' adjoining feeding section (hopper) was maintained at a lowest temperature and 'heater 3' near die section at a highest temperature. The selection of temperature range of heaters depends upon the material to be processed. The 'thermocouple 1' measures the average temperature of 'heater 1 and 2', whereas 'thermocouple 2' measures the temperature of 'heater 3'. The average value of heat input available at 'thermocouple 1' and 'thermocouple 2' was considered as mean barrel temperature. This mean barrel temperature was kept judicially in the range of $180-195{ }^{\circ} \mathrm{C}$ based upon pilot study conducted. In this work, the water tank temperature was kept at room temperature $\left(35^{\circ} \mathrm{C}\right)$. As the dimensional variation of filament diameter is a critical parameter and large variations on diameter adversely affect the FDM process but throughout the experimentation it was easily controlled within the specified limits $(1.75 \pm 0.03 \mathrm{~mm})$ by adjusting the speed of take up unit.

Nylon6 and Fe powder (300 mesh) are mixed in the required proportions, and the mixture is then fed into the hopper (Fig. 4a). The mixture flows by gravity from the hopper to the barrel of the single screw extruder and fills the annular space between the extruder screw and barrel (Fig. 4b). Barrel is stationary and screw is rotating, so there is a resistance to the flow of material due to friction and force is required to push the material towards the die. As the melting point of plastic exceeded, a thin film of composite material as compounded will form at the barrel surface. In the melt-conveying zone, material is simply forced towards die head (see Fig. 4c). The material through the die opening is carried away through water tank by a take up roller (Fig. 4d) and winded on spool on a winding

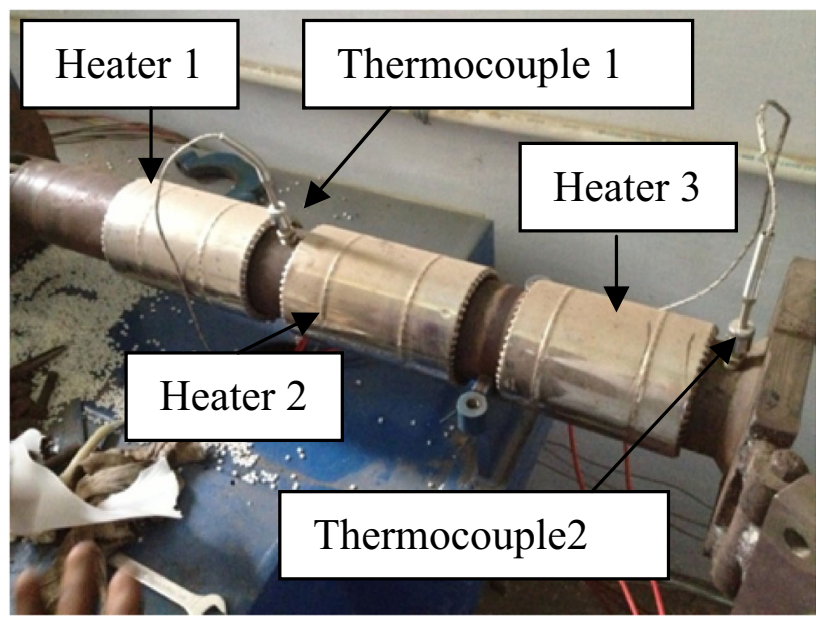

Fig. 3 3D view of heating arrangement of barrel for single screw extruder

machine. The material is fed at a constant rate through the hopper and the parameters which vary with the type of composition include the barrel temperature, die temperature, screw speed, the speed of the winding machine and the Melt flow Index corresponding to the composition of the material. The developed wire is first tested mechanically on universal testing machine for peak strength as per ASTM-D-638 standard to check its suitability and compatibility before feeding to FDM system.

\section{Model development for ultimate strength}

The literature review reveals that some experimental studies have been reported for inhouse development of FDM filament. But hitherto, very less has been reported on modelling the strength of (Nylon6 $+\mathrm{Fe}$ powder) 

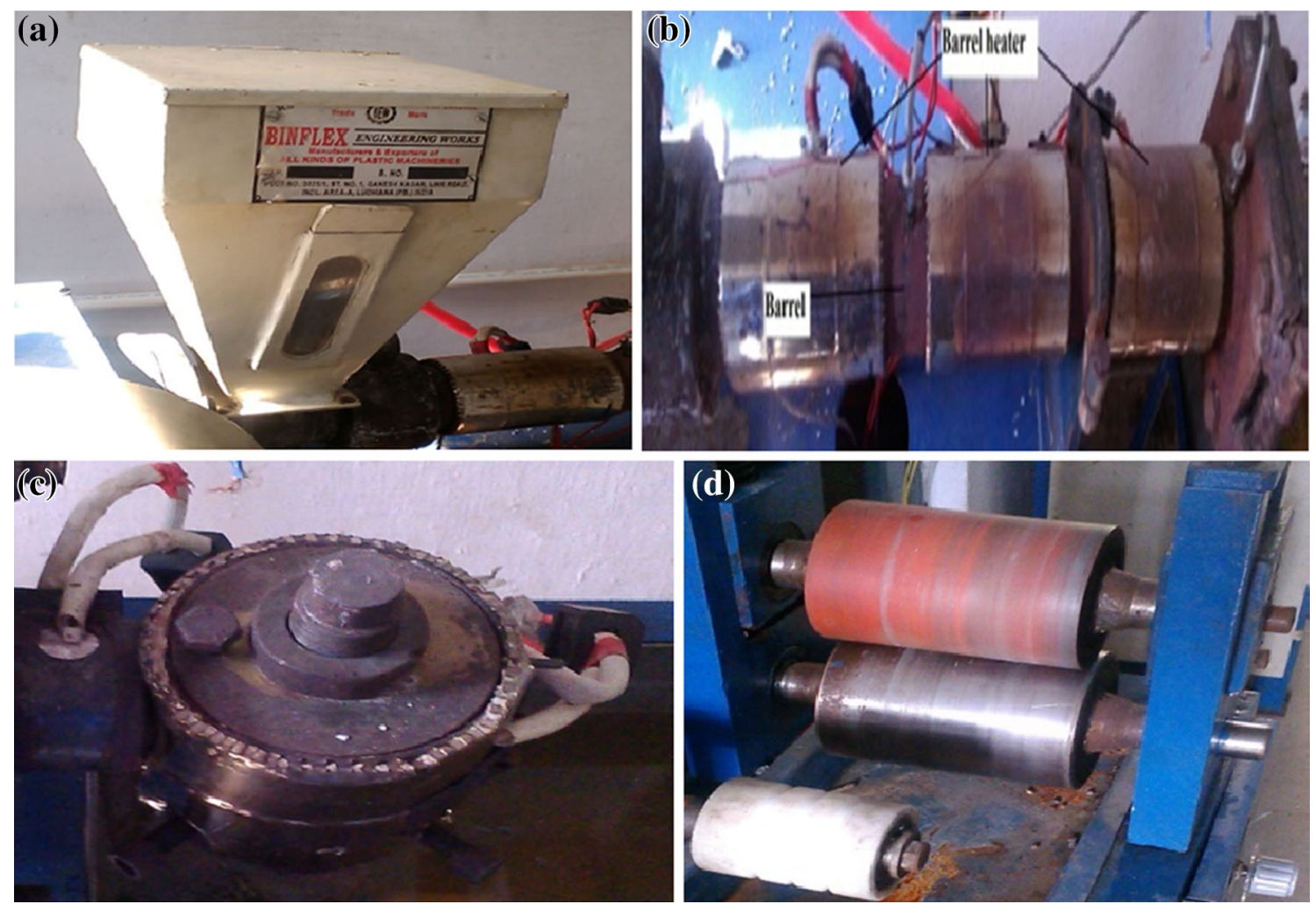

Fig. 4 Feed hopper (a), screw barrel (b), die head (c) and take up roller (d)

composite wire to be used as FDM filament. So in the present, work effort has been made to model the tensile strength (as per ASTM D638) of composite wire in a way that the newly developed wire may be used directly in commercial FDM setup (u-PrintSE, Stratasys, USA), without any change in hardware/software of the system.

The parameters used for wire development include temperature of barrel, temperature of die, the speed of the screw, the speed of the winder and the melt flow index corresponding to the varying proportion of the composition. The feed rate was fixed through the opening in the hopper. The output was taken as the peak strength. The diameter of the wire was kept fixed keeping in view the use of the wire in the FDM machine. Optimisation of the parameters was carried out using the RSM approach [22]. The historical data used are shown in Table 2.

The evaluation of the model was done considering it to be a polynomial with linear order and the response was taken for design purpose only. It was observed that under these conditions, no aliases are found for a linear model. Results for ANOVA are shown in Table 3.

Upon application of ANOVA, it has been observed that the model is significant as there are only $0.01 \%$ chances that an F value could be as large as '1413.12'. Further, $P$ value (probability less than 0.0500 ) indicates that the terms of the model are significant. In the current setup, it is observed that barrel temperature, die temperature, screw speed, the speed of the winding machine and melt flow index are significant terms in the model. Table 4 shows $R$ square values for model validation.

As observed from Table 4, it has been found that the predicted R-square is '0.9956' which has reasonable agreement with adjusted $R$-squared of ' 0.9970 ' as the difference between these two is less than 0.20 . There is an adequate precision which is an indication of signal-to-noise ratio. The ratio that is desirable is 4 , but in the present case, the value is 103.824 which indicate an adequate signal.

Based on the above facts, the model is significant following Eq. (1):

$$
\begin{aligned}
\text { Ultimate strength }= & 315.00962-2.85509 \mathrm{X}_{1} \\
& +1.06334 \mathrm{X}_{2}+2.1835 \mathrm{X}_{3} \\
& +0.4331 \mathrm{X}_{4}-6.71484 \mathrm{X}_{5} .
\end{aligned}
$$

In order to validate the above equation, a corollary has been made with the following values of process variables: $X_{1}-194{ }^{\circ} \mathrm{C}, X_{2}-209^{\circ} \mathrm{C}, X_{3}-30 \mathrm{rpm}, X_{4}-9 \mathrm{rpm}$ and $X_{5}-2.56 \mathrm{~g} / 10 \mathrm{~min}$.

It has been observed that the value of ultimate tensile strength predicted through the model and calculated through experimentation is ' $35.57 \mathrm{MPa}$ ' and $35.86 \mathrm{MPa}$, 
Table 2 Historical data sheet for peak strength

\begin{tabular}{|c|c|c|c|c|c|c|c|}
\hline $\begin{array}{l}\text { Run } \\
\text { no. }\end{array}$ & $\begin{array}{l}\text { Proportion of } \mathrm{Fe}-\mathrm{Nylon} 6 \\
\text { composite by weight }\end{array}$ & $\begin{array}{l}\text { Barrel } \\
\text { temperature } \\
\left({ }^{\circ} \mathrm{C}\right)\end{array}$ & $\begin{array}{l}\text { Die } \\
\text { temperature } \\
\left({ }^{\circ} \mathrm{C}\right)\end{array}$ & $\begin{array}{l}\text { Screw } \\
\text { speed }(\mathrm{rpm})\end{array}$ & $\begin{array}{l}\text { Winding machine } \\
\text { speed (rpm) }\end{array}$ & $\begin{array}{l}\text { Melt flow index } \\
(\mathrm{g} / 10 \mathrm{~min})\end{array}$ & $\begin{array}{l}\text { Peak } \\
\text { strength } \\
(\mathrm{MPa})\end{array}$ \\
\hline 1 & $50 \%$ Fe-50\% Nylon6 & 180 & 196 & 23 & 9 & 5.40 & 27.87 \\
\hline 2 & & 182 & 197 & 24 & 8 & 5.35 & 24.8 \\
\hline 3 & & 181 & 196 & 23 & 9 & 5.42 & 23.99 \\
\hline 4 & & 183 & 197 & 24 & 10 & 5.36 & 22.95 \\
\hline 5 & & 183 & 198 & 24 & 9 & 5.24 & 24.20 \\
\hline 6 & & 183 & 199 & 23 & 9 & 5.39 & 22.01 \\
\hline 7 & & 184 & 199 & 25 & 10 & 5.41 & 23.62 \\
\hline 8 & & 185 & 200 & 25 & 9 & 5.42 & 21.70 \\
\hline 9 & & 186 & 202 & 26 & 9 & 5.38 & 23.12 \\
\hline 10 & $55 \% \mathrm{Fe}-45 \%$ Nylon6 & 187 & 201 & 26 & 10 & 3.54 & 32.03 \\
\hline 11 & & 188 & 202 & 27 & 8 & 3.63 & 31.20 \\
\hline 12 & & 187 & 202 & 26 & 8 & 3.81 & 30.16 \\
\hline 13 & & 188 & 203 & 27 & 9 & 3.68 & 32.11 \\
\hline 14 & & 189 & 204 & 27 & 9 & 3.74 & 30.56 \\
\hline 15 & & 189 & 204 & 28 & 9 & 3.66 & 32.55 \\
\hline 16 & & 190 & 205 & 28 & 8 & 3.71 & 30.58 \\
\hline 17 & $60 \%$ Fe-40\% Nylon6 & 191 & 206 & 29 & 10 & 2.88 & 37.14 \\
\hline 18 & & 192 & 206 & 30 & 10 & 2.92 & 36.12 \\
\hline 19 & & 193 & 208 & 30 & 9 & 2.76 & 35.97 \\
\hline 20 & & 194 & 208 & 29 & 9 & 2.30 & 34.30 \\
\hline 21 & & 194 & 209 & 30 & 8 & 2.41 & 35.99 \\
\hline 22 & & 195 & 209 & 29 & 9 & 2.01 & 34.10 \\
\hline
\end{tabular}

Table 3 Analysis of variance table (partial sum of squares-Type III)

\begin{tabular}{lclrr}
\hline Source & Sum of squares & Degree of freedom & Mean square & $F$ value \\
\hline Model & 575.35 & 5 & 115.07 & 1413.12 \\
Barrel temperature $\left(X_{1}\right)$ & 33.19 & 1 & 33.19 & 0.0001 \\
Die temperature $\left(X_{2}\right)$ & 6.05 & 1 & 6.05 & 407.54 \\
Barrel speed $\left(X_{3}\right)$ & 35.48 & 1 & 35.48 & 74.35 \\
Speed of winding machine $\left(X_{4}\right)$ & 1.65 & 1 & 1.65 & 435.76 \\
Melt flow Index $\left(X_{5}\right)$ & 118.59 & 1 & 118.59 & 0.0001 \\
\hline
\end{tabular}

Table 4 Value of $R$-squared

\begin{tabular}{lc}
\hline Parameter & \multicolumn{1}{c}{ Value } \\
\hline$R$-squared & 0.9977 \\
Adjusted $R$-squared & 0.9970 \\
Predicted $R$-squared & 0.9956 \\
Adequate precision & 103.824 \\
\hline
\end{tabular}

respectively, shows a good agreement. In the present study, model for the peak strength has been prepared only (as because for FDM based extrusion one has to work beyond elastic limits, Young modulus has not been modelled in the present study). However, the percentage elongation has been measured which was within the range of $5-6 \%$.

\section{Results and discussions}

The historical data sheet for peak strength (see Table 5) of external studentized residual and internal studentized residual show that the model is significant with the two parameters, being under the desired limits. External studentized residual tests whether the run in question follows the model with coefficients estimated from the rest of the runs, i.e. whether the run is consistent with the rest of the data for this model. It is calculated by leaving the run in question out of the analysis and the responses are estimated from the remaining runs. The internal studentized residual is calculated by dividing the residual by the estimated 
Table 5 Analysis of historical data sheet for peak strength

\begin{tabular}{|c|c|c|c|c|c|c|c|}
\hline $\begin{array}{l}\text { Run } \\
\text { order }\end{array}$ & $\begin{array}{l}\text { Proportion of } \mathrm{Fe}-\mathrm{Nylon} 6 \\
\text { composite by weight }\end{array}$ & $\begin{array}{l}\text { Predicted } \\
\text { value }\end{array}$ & Residual & Leverage & $\begin{array}{l}\text { Internally studentized } \\
\text { residual }\end{array}$ & $\begin{array}{l}\text { Externally studentized } \\
\text { residual }\end{array}$ & $\begin{array}{l}\text { Cooks } \\
\text { distance }\end{array}$ \\
\hline 1 & \multirow[t]{9}{*}{$50 \% \mathrm{Fe}-50 \%$ Nylon6 } & 27.3676 & 0.5024 & 0.4508 & 2.3755 & 2.8588 & 0.7719 \\
\hline 2 & & 24.8069 & -0.0069 & 0.2945 & -0.0289 & -0.0280 & 0.0001 \\
\hline 3 & & 24.3782 & -0.3882 & 0.1792 & -1.5017 & -1.5688 & 0.0821 \\
\hline 4 & & 22.7509 & 0.1991 & 0.3767 & 0.8837 & 0.8773 & 0.0786 \\
\hline 5 & & 24.1869 & 0.0131 & 0.1020 & 0.0483 & 0.0468 & 0.00004 \\
\hline 6 & & 22.0595 & -0.0495 & 0.4423 & -0.2325 & -0.2255 & 0.0071 \\
\hline 7 & & 23.8703 & -0.2503 & 0.2388 & -1.0052 & -1.0055 & 0.0528 \\
\hline 8 & & 21.5783 & 0.1217 & 0.2678 & 0.4985 & 0.4865 & 0.0152 \\
\hline 9 & & 23.3020 & -0.1820 & 0.4030 & -0.8253 & -0.8167 & 0.0766 \\
\hline 10 & \multirow[t]{7}{*}{$55 \% \mathrm{Fe}-45 \%$ Nylon6 } & 32.1720 & -0.1420 & 0.3206 & -0.6035 & -0.5911 & 0.0286 \\
\hline 11 & & 31.0932 & 0.1068 & 0.3555 & 0.4663 & 0.4546 & 0.0200 \\
\hline 12 & & 30.5561 & -0.3961 & 0.1927 & -1.5448 & -1.6216 & 0.0949 \\
\hline 13 & & 32.2539 & -0.1439 & 0.0861 & -0.5274 & -0.5152 & 0.0044 \\
\hline 14 & & 30.0592 & 0.5008 & 0.0758 & 1.8254 & 1.9863 & 0.0455 \\
\hline 15 & & 32.7799 & -0.2299 & 0.1197 & -0.8588 & -0.8513 & 0.0167 \\
\hline 16 & & 30.2193 & 0.3607 & 0.2023 & 1.4151 & 1.4649 & 0.0846 \\
\hline 17 & \multirow[t]{6}{*}{$60 \% \mathrm{Fe}-40 \%$ Nylon6 } & 37.0506 & 0.0894 & 0.3381 & 0.3850 & 0.3745 & 0.0126 \\
\hline 18 & & 36.1104 & 0.0096 & 0.3855 & 0.0427 & 0.0414 & 0.0002 \\
\hline 19 & & 36.0233 & -0.0533 & 0.1988 & -0.2087 & -0.2024 & 0.0018 \\
\hline 20 & & 34.0736 & 0.2264 & 0.2657 & 0.9261 & 0.9217 & 0.0517 \\
\hline 21 & & 36.1487 & -0.1587 & 0.2579 & -0.6454 & -0.6333 & 0.0241 \\
\hline 22 & & 34.2291 & -0.1291 & 0.4464 & -0.6081 & -0.5957 & 0.0497 \\
\hline
\end{tabular}

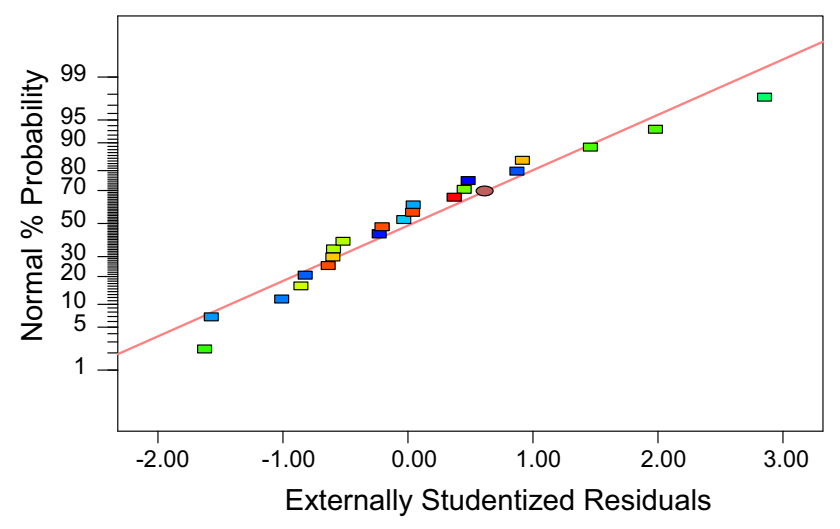

Fig. 5 Variation of normal \% probability with respect to externally studentized residuals for peak strength

standard deviation of that residual, and it gives the measure of the number of standard deviations separating the actual and predicted values.

The normal probability plot (see Fig. 5) compares the distribution of the residuals to a normal percentage (\%) probability for peak strength. The plot clearly shows that there is a probability of $50 \%$ that the values of residuals will lie near ' 0 ' and these will be majority in number and the remaining residuals will be in the range of -0.805 to +0.482 (where residuals is the difference between the actual and the predicted value). The data and the graph give an indication that the residuals will follow the normal distribution curve.

The residual and predicted plot (see Fig. 6) checks for constant variance across the range of predictions as compared to the residual for peak strength. As the points are randomly scattered between the extreme red lines, it is confirmed that there is a constant variance in the data.

Figure 7 shows the plot between the predicted and the actual values of peak strength. This is primarily used to detect a value or group of values which have not been predicted well by the model. As observed from Fig. 7, predicted value and the actual values are close to each other which signifies that the developed model is accurate and gives consistent results.

The Cook's distance (see Fig. 8) is a measure of how much the regression changes if the case is omitted from the analysis. All the points as per the runs are within the defined limits which signify that the model is significant. No two points are at a considerable distance from each other except for run number 1 which is at a greater distance 


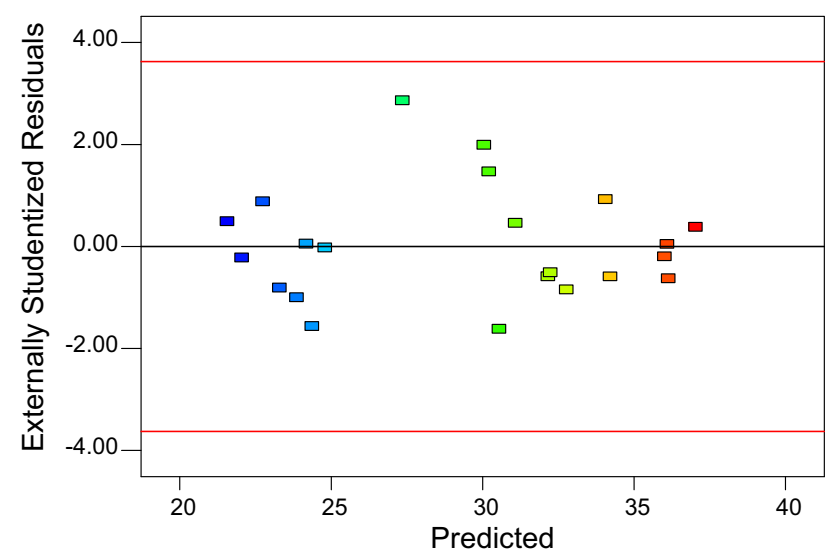

Fig. 6 Variation of externally studentized residuals with respect to predicted data plot for peak strength

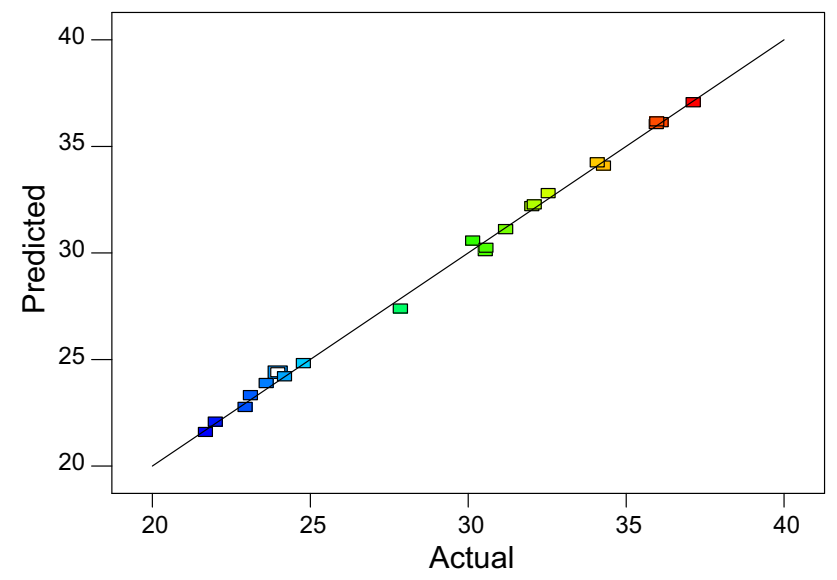

Fig. 7 Variation of predicted and actual data plot for peak strength

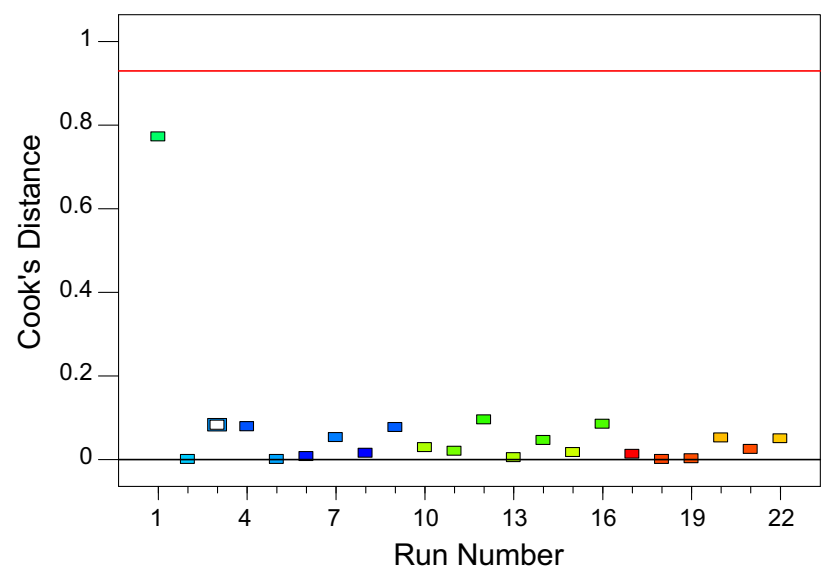

Fig. 8 Variation of Cook's distance with respect to run number for peak strength

relative to the other points but the run 1 is again within the defined limits. Leverage is a measure as to how each point influences the model fit. The point having leverage of 1.0

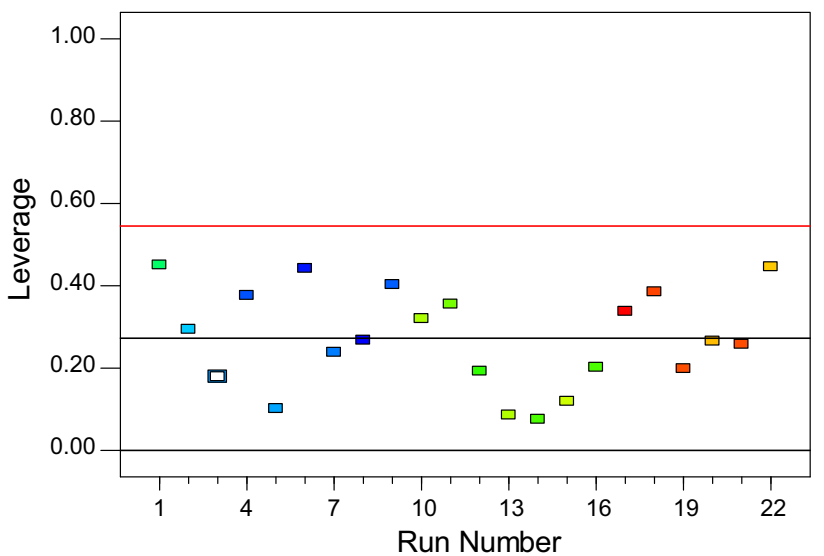

Fig. 9 Variation of leverage with respect to run number for peak strength

or very close to 1 means that the model exactly fits that point and that point controls the model.

Figure 9 shows that the leverage of none of the points is near 1 which again is an indication of a good model.

The optimization of the parameters has been carried out using design expert software and number of optimal solutions has been listed. The parameters selected, by keeping the maximum peak strength as the goal, are given in Table 6.

Melt flow index of $2.41 \mathrm{~g} / 10 \mathrm{~min}$ was taken as the value of MFI for ABS is in the similar range at $230{ }^{\circ} \mathrm{C}$ and $3.8 \mathrm{~kg}$ load. Based on the above parameters, the peak strength comes out to $42.379 \mathrm{MPa}$ which is comparable with the peak strength of ABS used in FDM machine.

Figure 10 shows the graph for desirability between the die temperature and the barrel temperature keeping the barrel speed as $27 \mathrm{rpm}$, speed of winding machine as $9.08 \mathrm{rpm}$ and melt flow index equals to $2.411 \mathrm{~g} / 10 \mathrm{~min}$ as per optimisation. From the graph, it is clear that the red shading gives the range which is desirable, while the other colour shadings give an indication of decreasing desirability. The optimum parameters that have been chosen have a desirable value of 1 and are suitable for further experimentation. Figure 11 shows the 3D model for desirability between the die temperature and the barrel temperature keeping the barrel speed as $30 \mathrm{rpm}$, speed of winding machine as $9 \mathrm{rpm}$ and melt flow index equals to $2.41 \mathrm{~g} / 10 \mathrm{~min}$ as per the optimised parameters. The horizontal portion that is parallel to the base gives the values of die temperature and the barrel temperature which are desirable having a desirability of 1 , whereas the inclined portion gives an indication of decreasing desirability. From the graph, it is clear that the values that have been optimised lie in the desirability range of 1 .

In order to confirm the distribution of the Fe particles in polymeric composites, SEM and EDS (as shown in 
Table 6 Optimum parameters for maximum peak strength

\begin{tabular}{lllll}
\hline Barrel temperature $\left({ }^{\circ} \mathrm{C}\right)$ & Die temperature $\left({ }^{\circ} \mathrm{C}\right)$ & Barrel speed $(\mathrm{rpm})$ & Speed of winding machine $(\mathrm{rpm})$ & Melt flow index $(\mathrm{g} / 10$ min) \\
\hline 188 & 204.49 & 27 & 9.08 & 2.411 \\
\hline
\end{tabular}

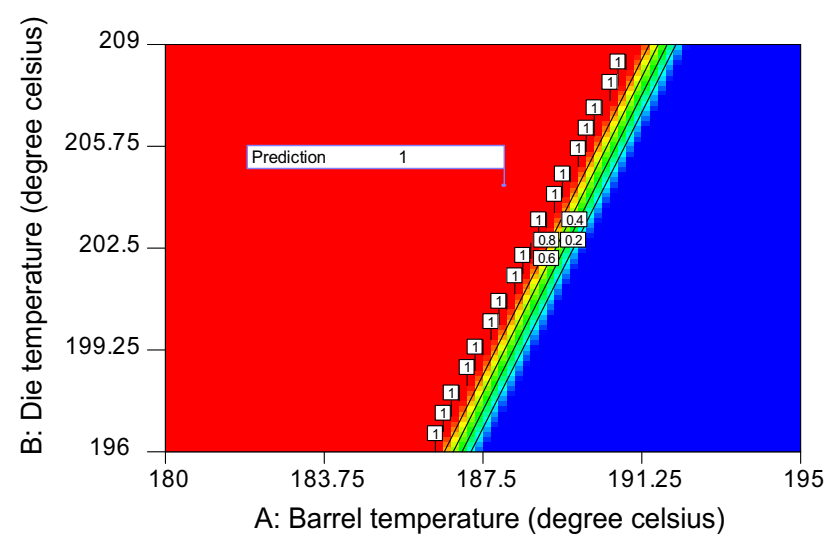

Fig. 10 Desirability contour for peak strength

Fig. 12) analyses have been carried out on test specimens of $5 \mathrm{~mm} \times 5 \mathrm{~mm} \times 5 \mathrm{~mm}$ size. Three compositions (as shown in Table 7) were compared for observing the particle distribution trend.

From the SEM-EDS plots (see Fig. 12), it has been observed that with increase in proportion of Fe particles, the filament prepared shows more homogeneity. As observed from Fig. 12a-c, the presence of Fe particles in the Nylon6 was increased, which has been confirmed through the respective EDS plots. This can be seen through visual inspection of the obtained pictures that the number of Fe particles shows an increasing trend as the composition changed from A to C. It can be summarised from microscopic investigations that the developed composite test part contained Fe particles which were evenly distributed, and an increase in percentage of Fe content has been observed with an increase in the wt $\%$ of Fe particles in filament. Moreover, proper bonding between the filler and binder has been seen without any occurrence of air gaps indicated toward the compatibility of Fe particles with Nylon6. The results are in line with the observations made by other investigators $[19,23]$.

The composite wire prepared has been used in FDM setup. Figures 13 and 14, respectively, shows printing of parts on u-Print SE FDM printer and samples of printed parts.

\section{Conclusions}

The materials presently used in commercial FDM setup are different polymers (like: ABS, Nylon6 etc.) and are usually patented and thus involves a high cost. In the present study, a new feedstock composite material has been developed inhouse which has certain additional tailor made properties, which increases the application domain of the composite at
Fig. 11 3D graph of desirability for peak strength

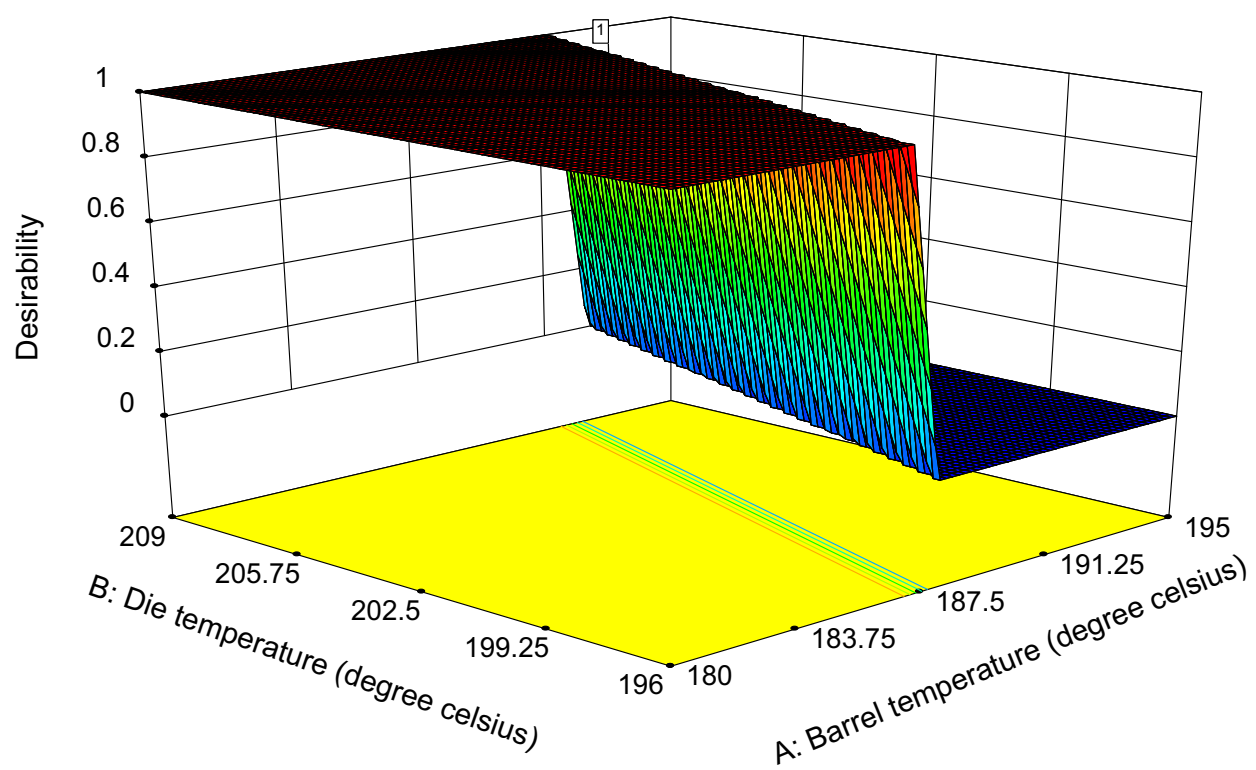


(a)
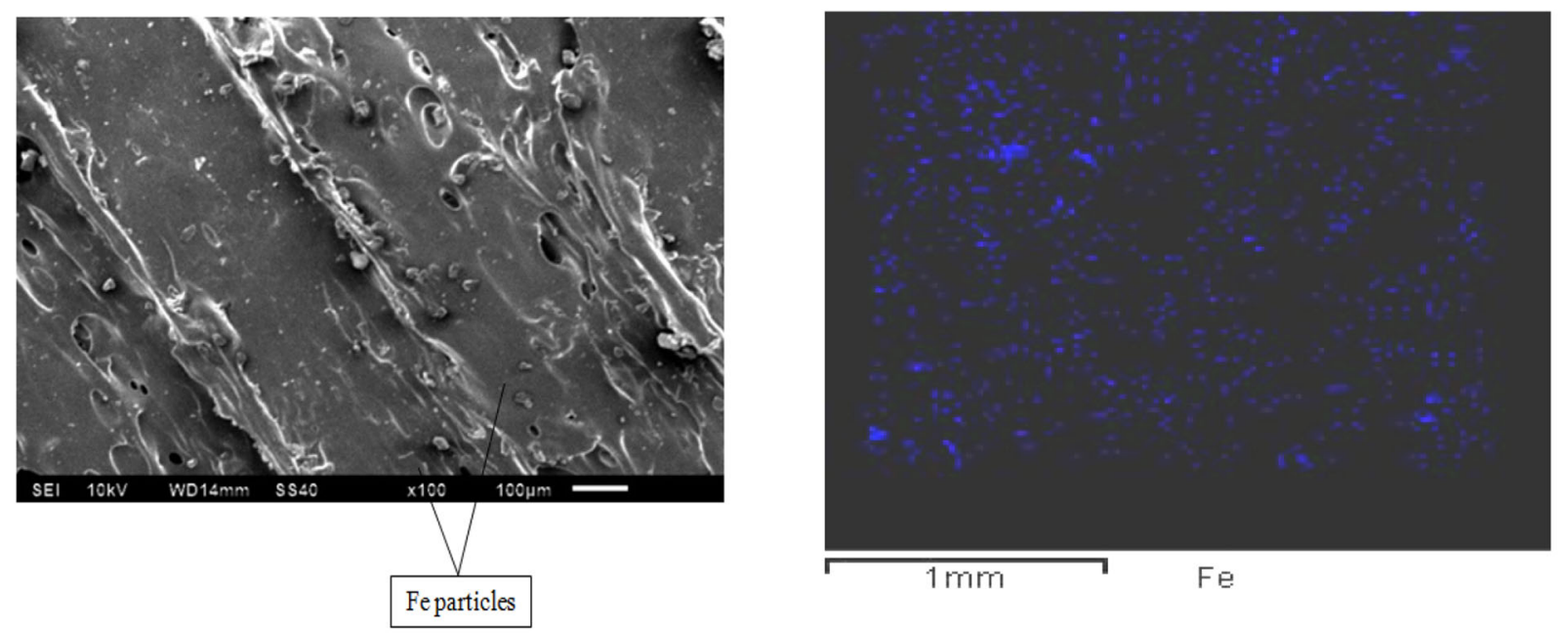

(b)
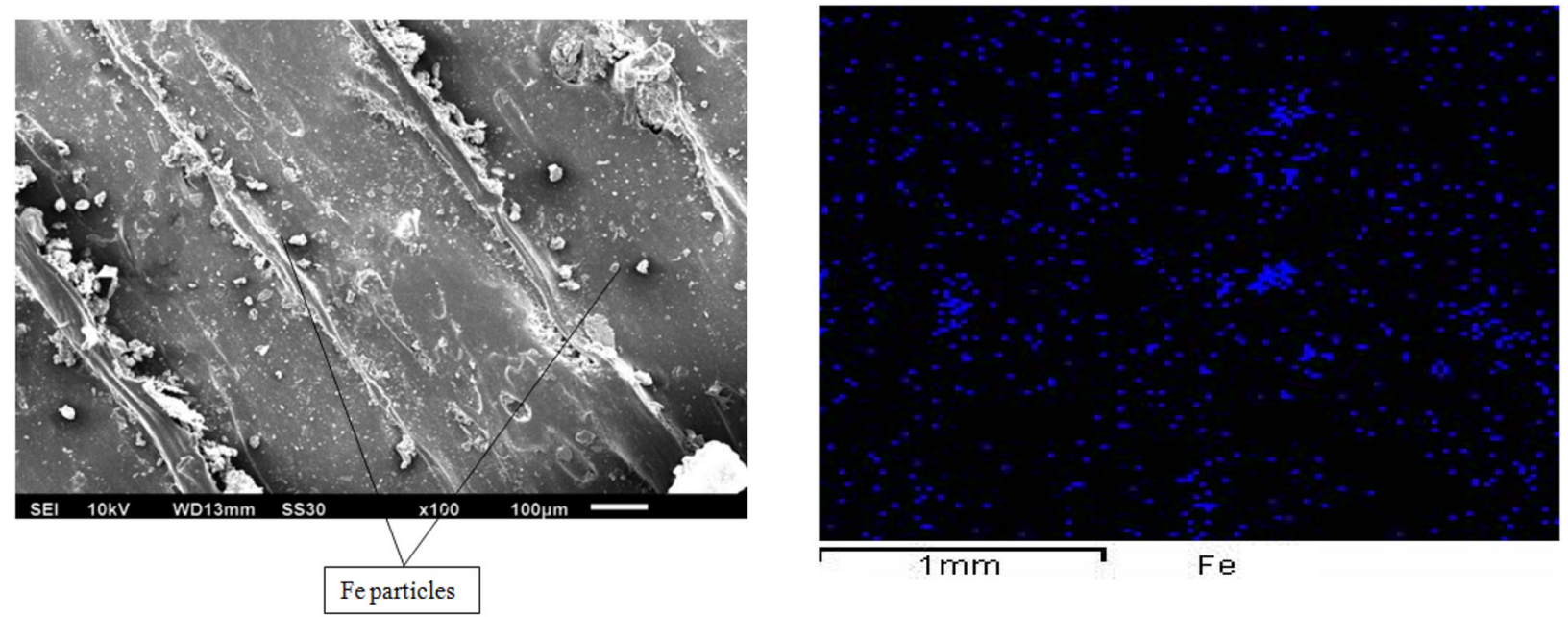

(c)
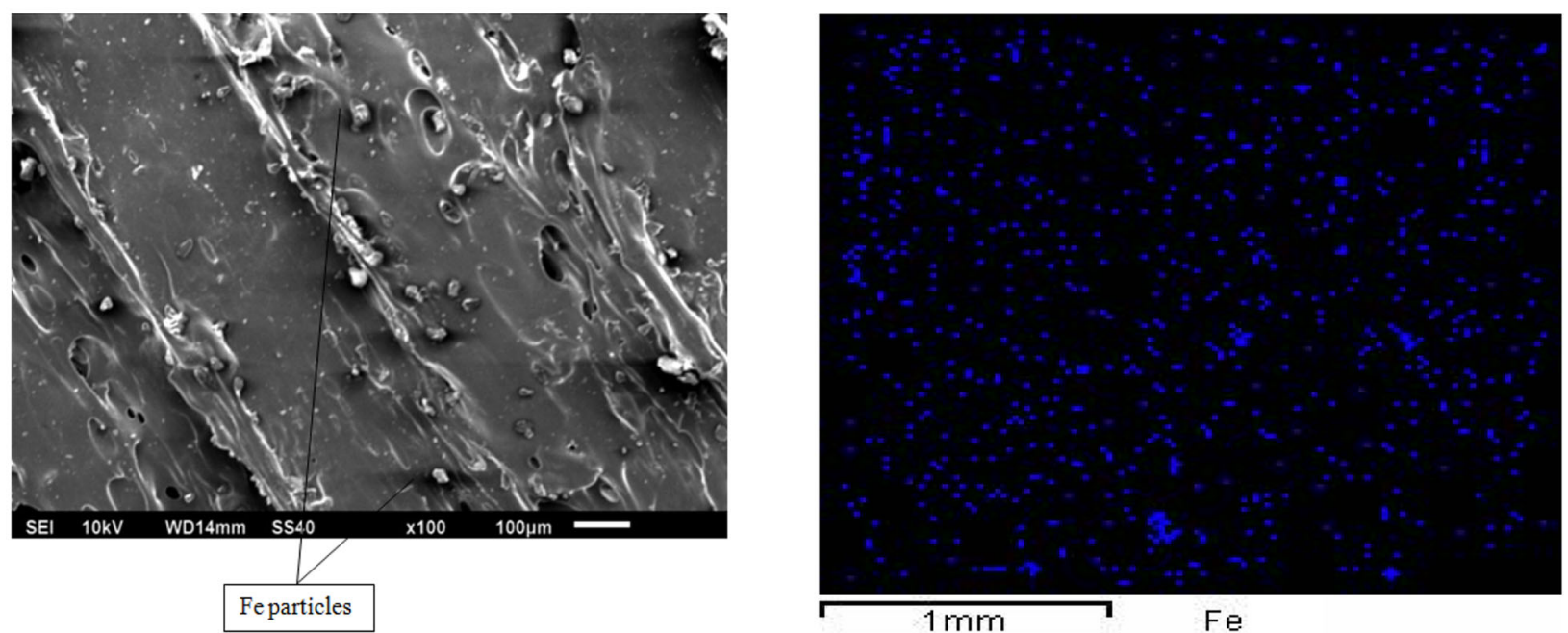

Fig. 12 SEM-EDS plots of composition A (a), composition B (b) and composition C (c) 
Table 7 Compositions of Fe-Nylon6 (in wt\%)

\begin{tabular}{lll}
\hline Composition & Nylon6 & Fe powder \\
\hline A & 50 & 50 \\
B & 45 & 55 \\
C & 40 & 60 \\
\hline
\end{tabular}

a lower cost. The results obtained after experimentation are summarised as below:

1. A composite feedstock filament which consists of $\mathrm{Fe}$ and Nylon6 has been developed that can be used in the existing FDM machine without any modifications. The proportion of the filler $(\mathrm{Fe})$ in Nylon6 has been established using the MFI as the reference and a loading of $60 \% \mathrm{Fe}$ in the composite gave a MFI equal to that of ABS that is currently put to use. In other words, the optimum levels of barrel temperature, die temperature, screw speed, speed of the winding machine were chosen by considering melt flow index as the reference property. The developed model for peak strength is significant. The predicted $R$-squared value is 0.9956 which is in reasonable agreement with adjusted $R$-squared value of 0.9970 . There is an adequate precision which is an indication of high signal-to-noise ratio. The ratio that is desirable is 4 , but in the present case, the value is 103.824 which indicate an adequate signal.

2. Accurate models have been developed for peak strength based on the input parameters of the screw extruder. The optimisation of the screw extruder parameters was performed using RSM through design expert software. The mechanical testing of wire fabricated at optimised parameters for composition which contains $60 \% \mathrm{Fe}$ and $40 \%$ Nylon6 on universal tensile testing machine gave the peak strength comparable with ABS material. The peak strength of the alternative FDM filament enabled successful run of this material without any feed stock filament breakage and change in hardware/software of the system.

3. From the SEM-EDS plots, it has been observed that the wt $\%$ content of Fe particles in Nylon-6 matrix was uniform in the filament/wire prepared. Since the composite developed in the present research work has ferromagnetic properties, it can be used in electrical/electronic/instrumentation sector.
Fig. 13 Printed cylindrical section (b) on u-print SE FDM setup section (a), printing of cubical
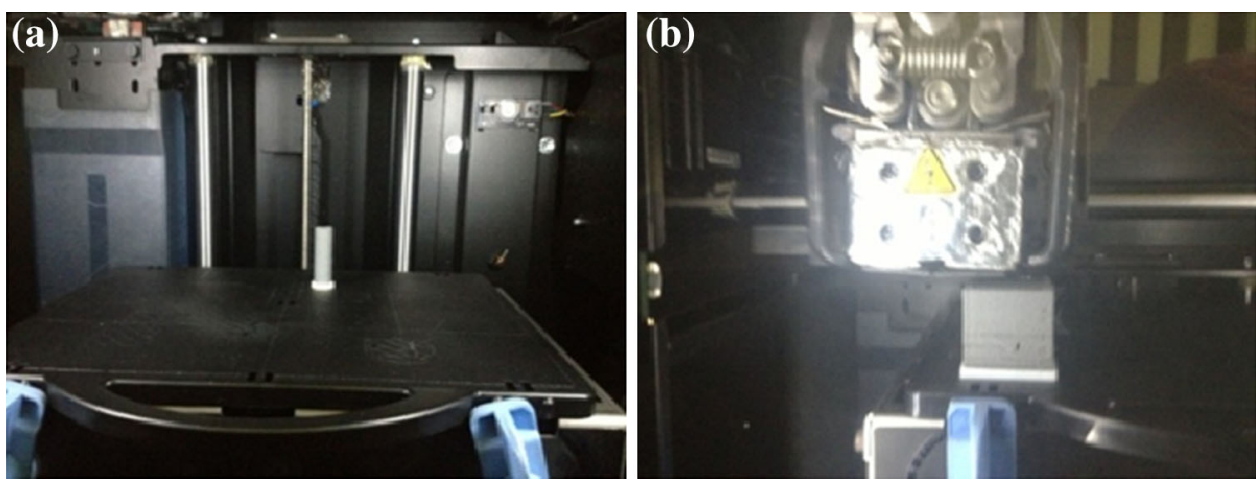

Fig. 14 Printing of non functional prototypes (a), printing of functional prototypes with different cut sections (b) on u-print SE FDM setup (a)

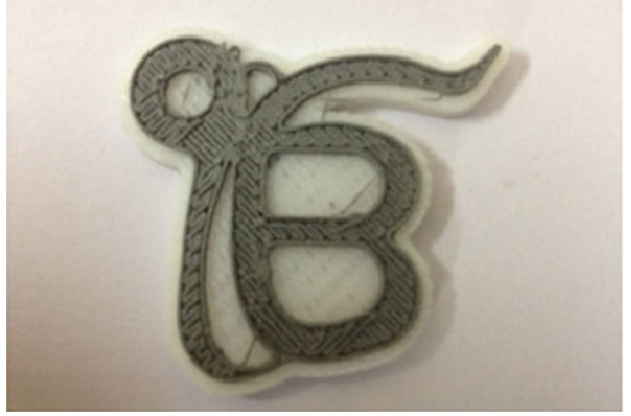

(b)

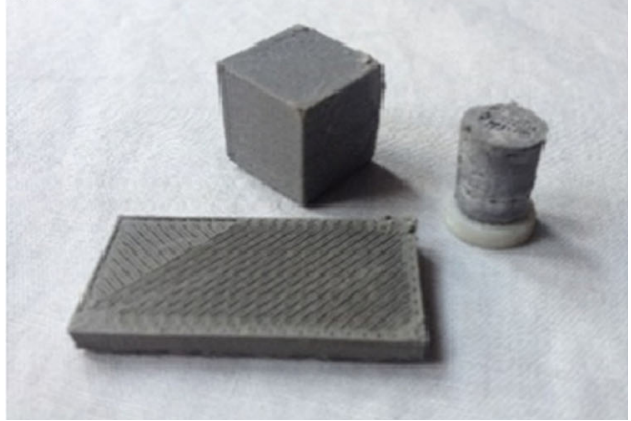


Acknowledgements The authors are thankful to manufacturing research lab, Production Engineering, Guru Nanak Dev Engineering College, Ludhiana (India) for technical support.

\section{References}

1. Garg HK, Singh R (2012) Experimental investigations for development of pattern for dies using FDM. Mater Sci Forum 701:77-83

2. Kumar P, Ahuja IPS, Singh R (2012) Application of fusion deposition modelling for rapid investment casting - a review. Int J Mater Eng Innov 3:204-227

3. Garg HK, Singh R (2012) Pattern development for manufacturing applications with fused deposition modelling-a case study. Int J Autom Mech Eng 7:981-992

4. Chabbra M, Singh R (2011) Rapid casting solution. Rapid Prototyp J 17:328-350

5. Jacobs PF, Hilton PD (2000) Rapid tooling and industrial applications. Marcel Dekker Ltd., ISBN-9780824787882, pp 10-18

6. Tromans G (2003) Developments in rapid casting. Professional Engineering, pp 14-20. ISBN: 186058390392

7. Wohlers TT (2006) Wohlers report 2006: RP, RT, RM state of the industry. Annual Worldwide Progress Report. Wohlers Associates Inc., Fort Collins $\mathrm{CO}$

8. Masood SH, Song WQ (2004) Development of new metal/polymer materials for rapid tooling using fused deposition modelling. Mater Des 25:587-594

9. Masood SH, Song WQ (2005) Thermal Characteristics of a new metal/polymer material for FDM rapid prototyping process. Assem Autom 25:309-315

10. Upcraft S, Fletcher R (2003) The rapid prototyping technologies. Assem Autom 23:318-330

11. Kruth JP (1991) Material manufacturing by rapid prototyping technologies. CIRF Annu 40:603-614
12. Agarwala MK, Van WR, Bandyopadhyay A, Whalen PJ, Safari A, Danforth SC (1996) Fused deposition of ceramics and metals: an overview. In: Proceedings of the Solid Freeform Fabrication Symposium, University of Texas, Austin, pp 385-392

13. Jain P, Kuthe AM (2013) Feasibility study of manufacturing using rapid prototyping: FDM approach. Proc Eng 63:4-11

14. Dyrbus G (2010) Investigation on quality of rapid prototyping FDM method. In: 14th International Research/Expert Conference, Trend in the development of Machinery and Associated Technology, 11-18th September, TMT 2010, Mediterranean Cruise

15. Lee CW, Chua CK, Cheah CM, Tan LH, Feng C (2004) Rapid investment casting: direct and indirect approaches via fused deposition modelling. Int J Adv Manuf Technol 23:93-101

16. Singh R (2014) Process capability analysis of fused deposition modelling for plastic components. Rapid Prototyp J 20:69-76

17. Bakar NSA, Alkahari MR, Boejang H (2010) Analysis on fused deposition modelling performance. J Zhejiang Univ Sci A 11:972-977

18. Rochus P, Plesseria JY, Elsen MV, Kruth JP, Carrusc R, Dormal $T$ (2007) New applications of rapid prototyping and rapid manufacturing (RP/RM). Act Astronautic 61:352-359

19. Singh R, Singh S (2014) Development of nylon based FDM filament for rapid tooling application. J Inst Eng 95:103-108

20. Zein I, Hutmacher DW, Tan KC, Teoh SH (2002) Fused deposition modeling of novel scaffold architectures for tissue engineering applications. Biomaterials 23:1169-1185

21. Das MK, Ghoshdastida PS (2002) Experimental validation of a quasi three-dimensional conjugate heat transfer model for the metering section of a single-screw plasticating extruder. J Mater Process Technol 120:397-411

22. Kumar R, Dhiman S (2013) A study of sliding wear behaviour of aluminium-7075 alloy and aluminium-7075 hybrid composite by RSM. Mater Des 50:351-359

23. Garg HK, Singh R (2015) Comparison of wear behavior of ABS and Nylon6-Fe powder composite parts prepared with fused deposition modelling. J Cent S Univ 22(10):3705-3711 